\title{
Performance of the Biocontrol Fungus Piriformospora indica on Wheat Under Greenhouse and Field Conditions
}

\author{
Albrecht Serfling, Stefan G. R. Wirsel, Volker Lind, and Holger B. Deising
}

\begin{abstract}
First, second, and fourth authors: Institut für Agrar- und Ernährungswissenschaften, Martin-Luther-Universität Halle-Wittenberg, LudwigWucherer-Str. 2, D-06099 Halle (Saale), Germany; and third author: Bundesanstalt für Züchtungsforschung an Kulturpflanzen, Institut für Epidemiologie und Resistenz, Theodor Roemer Weg 4, D-06449 Aschersleben, Germany.
\end{abstract}

Accepted for publication 5 October 2006.

\begin{abstract}
Serfling, A., Wirsel, S. G. R., Lind, V., and Deising, H. B. 2007. Performance of the biocontrol fungus Piriformospora indica on wheat under greenhouse and field conditions. Phytopathology 97:523-531.

The endophyte Piriformospora indica colonizes roots of a range of host plants and increases biomass production and resistance to fungal pathogens and, thus has been considered a biocontrol fungus. However, the field performance of this fungus has not yet been tested in temperate climates. Therefore, we evaluated the performance of this fungus in different substrata under greenhouse and practical field conditions. Roots of winter wheat were colonized efficiently, and biomass was particularly

symptoms caused by the leaf pathogen did not differ in Piriformospora indica-colonized compared with control plants. In the field, Pseudocercosporella herpotrichoides disease severity was significantly reduced in plants colonized by the endophyte. Increased numbers of sheath layers and hydrogen peroxide concentrations after B. graminis attack were detected in Piriformospora indica-colonized plants, suggesting that root colonization causes induction of systemic resistance or priming of the host plant. Although the endophyte is not well suited for growth at Central European temperature conditions, it remains to be shown whether $P$. indica is more suitable for tropical or subtropical farming.
\end{abstract} increased on poor substrata. In greenhouse experiments, symptom severity of a typical leaf (Blumeria graminis f. sp. tritici), stem base (Pseudocercosporella herpotrichoides), and root (Fusarium culmorum) pathogen was reduced significantly. However, in field experiments,
Additional keywords: arbuscular mycorrhizal fungi, powdery mildew, systemic acquired resistance.
Traditionally, fungi have been regarded as pathogens by agronomists. However, in recent years, symbiotic fungi providing benefits to crop plants have become an additional focus of research. In addition to the arbuscular mycorrhizal fungi (AMF) that constitute a distinct fungal phylum, the Glomeromycota (22), endophytes that mainly belonging to the Ascomycota or Basidiomycota, have been shown to improve the vigor of their hosts $(5,9,20,26)$. One particular endophyte, Piriformospora indica, a member of the Sebacinales order of the Basidiomycota, recently has received some attention. Originally, this fungus was recovered from the rhizosphere of shrubs growing in the Thar desert of Rajasthan, India $(24,27)$. In contrast to the obligate biotrophic AMF, $P$. indica can be cultivated easily on synthetic media, where it forms typical pear-shaped chlamydospores. Earlier work established that $P$. indica increased the biomass of several host plants belonging to a wide range of taxa $(24,26,28)$. This fungus even colonized mustard, cabbage, and spinach that belong to the Brassicaceae, which do not form a symbiosis with AMF (14). The enhanced biomass of the host apparently results from improved nutrient supply. In particular, $P$. indica seems to mediate phosphorous and nitrogen uptake from the soil $(23,25)$. Recent work suggested that $P$. indica stimulates NADH-dependent nitrate reductase activity in roots of Arabidopsis and tobacco (23). Enhanced enzymatic activity correlated with an increased transcription of the corresponding plant gene. Thus, it seems that $P$. indica mediates nitrate uptake from the soil, which is in contrast

Corresponding author: H. B. Deising

E-mail address: holger.deising@landw.uni-halle.de

doi:10.1094/PHYTO-97-4-0523

(C) 2007 The American Phytopathological Society to AMF, where nitrogen is preferentially absorbed as ammonium. Beyond the stimulating effect on biomass production, $P$. indica apparently supports its host by protecting it from pathogenic fungi (28). It was suggested that $P$. indica may target an as-yetunidentified signaling pathway to induce systemic resistance.

The beneficial effects promoted by $P$. indica have been determined mostly in small-scale greenhouse or growth-chamber experiments. Recently, the effect of $P$. indica on barley was assessed under seminatural conditions using Mitscherlich pots (28). In this work, the interaction between the plant and the fungus had been established in growth chambers, followed by incubation outdoors. Under these conditions, $P$. indica acted as both a biofertilizer and a biocontrol agent. However, there is no information available yet on whether or not the benefits described from greenhouse experiments also would occur in fields managed under regular farming practices. Here, we investigate whether $P$. indica also stimulates the production of biomass in wheat. Another objective of this study was to determine whether the inoculation of wheat with $P$. indica may subsequently reduce the symptoms caused by several fungal pathogens on leaves, stems, and roots. These objectives were addressed under greenhouse and field conditions.

\section{MATERIALS AND METHODS}

Cultivation of fungi. $P$. indica strain DSM 11827 (obtained from P. Franken, Leibniz Institute of Vegetable and Ornamental Crops, Grossbeeren, Germany) and Fusarium culmorum strain GU75 (obtained from U. Sperling, Landesanstalt für Landwirtschaft, Forsten und Gartenbau, Magdeburg, Germany) were grown on complete medium agar at ambient temperature (15). 
Pseudocercosporella herpotrichoides strain Phh31/3 (obtained from V. Lind, BAFZ Aschersleben, Germany) was grown on $1.5 \%$ water agar at $23^{\circ} \mathrm{C}$. Blumeria graminis f. sp. tritici strain KF01 (obtained from S. Reimann, Martin Luther Universität, Halle, Germany) was propagated in the greenhouse at ambient temperature on wheat cv. Kanzler.

To produce inoculum for infection assays, $P$. indica and $F$. culmorum were grown without shaking at room temperature in a volume of 1.5 liter of liquid complete medium (15). After 21 days of growth, the fresh weight of the mycelial fraction accounted for $\approx 220 \mathrm{~g}$. The mycelia were minced for 5 min using a rotor-stator homogenizer (Ultra Turrax, model T8; IKA Labortechnik GmbH, Staufen, Germany) at the lowest speed setting and then immediately used for inoculation. For field experiments, the suspension of $P$. indica was diluted twofold with tap water prior to usage. To produce inoculum of Pseudocercosporella herpotrichoides, the fungus was grown on $1.5 \%$ water agar under longwave UV light for 28 days at $23^{\circ} \mathrm{C}$ (Incubator CIR 350; UniEquip GmbH, Martinsried, Germany). Agar blocks were crushed with a pestle in sterile distilled water. Spores then were passed through a nylon filter (mesh width, $0.5 \mathrm{~mm}$ ) and adjusted to a final concentration of $1 \times 10^{4} \mathrm{ml}^{-1}$.

Mycelial growth rates of Piriformospora indica and Pseudocercosporella herpotrichoides were assayed in the dark on complete medium agar (15) using three replicated cultures for each temperature. These ranged from 5 to $35^{\circ} \mathrm{C}$ at intervals of $5^{\circ} \mathrm{C}$. Colony diameters were recorded every other day for 20 days in total. The respective data of the triplicates were combined and averaged.

DNA isolation and PCR to detect $P$. indica in infected plants. Wheat roots inoculated with Piriformospora indica were harvested from pot cultures and total genomic DNA was extracted from $\approx 100 \mathrm{mg}$ of tissue, following the instructions provided by the manufacturer of a commercial kit (DNA Plant mini Kit; Qiagen AG, Hilden, Germany). DNA also was isolated from roots of uninoculated plants, and from mycelia harvested by filtration from liquid cultures that were produced as described above to serve as negative and positive controls, respectively, in polymerase chain reaction (PCR) experiments.

We used the annotated sequence (AJ459235) of the $\beta$-tubulin gene of $P$. indica to design specific primers and to develop an assay for its detection in host tissues. Primers had the sequences 5'-TTCTGGGAAGTCGTCTCTG-3' and 5'-AGCCAACCATGAAGAAGTG-3'. In a total volume of $20 \mu \mathrm{l}$, PCR reactions included $0.25 \mu \mathrm{M}$ each primer, $2.5 \mathrm{mM} \mathrm{MgCl}$, $0.5 \mathrm{mM}$ dNTPs, $1 \times$ reaction buffer, Taq polymerase at $0.4 \mathrm{U} / \mu \mathrm{l}$ (all reagents from MBI Fermentas GmbH, St Leon-Roth, Germany), and $100 \mathrm{ng}$ of template DNA. Cycling conditions were $95^{\circ} \mathrm{C}$ for $180 \mathrm{~s}$; followed by 35 cycles of $95^{\circ} \mathrm{C}$ for $30 \mathrm{~s}, 51.5^{\circ} \mathrm{C}$ for $30 \mathrm{~s}$, and $72^{\circ} \mathrm{C}$ for $90 \mathrm{~s}$; and a final extension at $72^{\circ} \mathrm{C}$ for $10 \mathrm{~min}$. Reaction products were analyzed by electrophoresis on a $1 \%$ agarose gel. Positive controls included DNA isolated from $P$. indica grown in vitro and produced a band of the anticipated size of $751 \mathrm{bp}$. Negative controls used either DNA from roots of noninoculated wheat or omitted any template DNA.

Infection assays using wheat pot cultures. Winter wheat (Triticum aestivum cv. Kanzler) (Saatzucht Engelen-Büchling e.K., Oberschneiding, Germany), which is highly susceptible to most fungal pathogens, was grown in the greenhouse in pots with a diameter of $13 \mathrm{~cm}$ and a height of $11.5 \mathrm{~cm}$. The temperature ranged from 22 to $30^{\circ} \mathrm{C}$ and the humidity was not controlled. The substratum used was either washed sand (average particle size 220 to $380 \mu \mathrm{m}$ ) (Redsun GmbH \& Co. KG, Kevelaer, Germany) or garden soil (Plantaflor GmbH, Vechta, Germany) that was pasteurized by steaming prior to application. Each variant included at least four pots with 4 plants so that a minimum of 16 plants was available. The pots were distributed in a randomized manner and their positions were exchanged once a week.
To determine the germination rate of wheat, $100 \mathrm{ml}$ of mycelial suspensions containing $\approx 15 \mathrm{~g}$ fresh weight each of $P$. indica or $F$. culmorum was produced as described above and poured onto the substratum immediately before the seed were sown. The controls were treated with $100 \mathrm{ml}$ of sterile medium. The results were scored after 7 days of incubation in the greenhouse under the same conditions as above.

For infection assays of wheat plantlets, $P$. indica generally was inoculated 7 days after sowing using the same type of suspension as described above. For dual inoculations, $P$. indica was inoculated 7 days after sowing and then, after an additional 7 days of incubation, challenge inoculation with a pathogen was carried out.

For infection assays of wheat plantlets involving $F$. culmorum, the inoculum was produced as described above. The fresh weights were recorded separately for roots and shoots of plants harvested after 30, 60, 90, and 120 days of growth in the greenhouse under the same conditions as above.

For infection assays of wheat plantlets involving $P$. herpotrichoides, the inoculum was generated as described above. Inoculation was carried out, without inflicting any physical damage to the tissue, by pipetting $800 \mu \mathrm{l}$ of a spore suspension $\left(1 \times 10^{4} \mathrm{ml}^{-1}\right)$ to the base of each wheat stem. The inoculated plants were incubated in environmentally controlled growth chambers (Model ILKA 2000/1; Maschinenfabrik Netzschkau, Germany) that were continuously run at $17^{\circ} \mathrm{C}$ and $76 \%$ relative humidity under $16 \mathrm{~h}$ of light at $200 \mu \mathrm{E} \mathrm{m} \mathrm{m}^{-2} \mathrm{~s}^{-1}$ at soil level. At 60 days postinoculation (dpi), fresh weights were recorded separately for roots and shoots. The symptoms were scored by a custom-designed scale that counted the number of brownish tissue layers at the stem base and expressed this as the fraction in percentage of the total layers developed.

For infection assays of wheat plantlets involving B. graminis $\mathrm{f}$. sp. tritici, the inoculum were dry conidia. Inoculation was performed by shaking infected, heavily sporulating wheat plants above noninfected tester plants. Incubation of the freshly inoculated plants continued in the greenhouse under the same conditions as described above. The numbers of mildew pustules per square centimeter were recorded separately for leaves L2 and L3 at 3, 6, and 9 dpi.

Microscopical techniques. Light microscopy was performed with a Nikon Eclipse 600 epifluorescence microscope (Nikon $\mathrm{GmbH}$, Düsseldorf, Germany). Digital images were taken with a CCD-1300 camera (VDS Vosskühler GmbH, Osnabrück, Germany) and archived and processed with the software package Lucia 4.61 (Nikon GmbH, Düsseldorf, Germany).

To detect hydrogen peroxide production after inoculation with powdery mildew, 1-cm-long segments from the middle of infected leaves (L3) were subjected to staining with 3,3-diaminobenzidine (DAB). For each variant, three-leaf segments were incubated for $8 \mathrm{~h}$ in $0.1 \%$ DAB (Sigma-Aldrich Chemie GmbH, Taufkirchen, Germany) with the $\mathrm{pH}$ adjusted to 3.8 by $\mathrm{HCl}$. The tissue then was incubated for $16 \mathrm{~h}$ in $80 \%$ ethanol, $0.15 \%$ trichloracetic acid, and $20 \%$ chloroform and stored in $50 \%$ glycerol.

To examine the colonization of Piriformospora indica in field samples after harvest, 16 root segments per variant were autoclaved in $10 \% \mathrm{KOH}$ and, afterward, again autoclaved in $0.03 \%$ chlorazol black $E$ in a 1:1:1 mixture of lactic acid, glycerol, and water. For each segment, 200 cells were analyzed and the fraction of cells harboring fungal spores was determined.

For microscopical studies of the interaction between $P$. indica and Pseudocercosporella herpotrichoides occurring in vitro, glass slides were covered with a thin layer of solid complete medium (15). The fungi were inoculated at a distance of $1 \mathrm{~cm}$ and al-lowed to grow for 7 days at $25^{\circ} \mathrm{C}$. The slides were incubated for $20 \mathrm{~min}$ in Calcoflour White M2R fluorescent brightener 28 (Sigma-Aldrich) $(0.01 \%$ in distilled water) and washed with $25 \%$ glycerol. Three replicates per variant were used to determine the distances between 50 hyphal tips and their respective first branches at the edge of the colony. 
Field experiments. Experiments were carried out in the 200203 and 2003-04 growing seasons at the field station of the Martin-Luther University Halle-Wittenberg situated at Bad Lauchstädt (federal state of Saxony-Anhalt, Germany, $113 \mathrm{~m}$ above sea level; GPS: field of 2002-03, $51^{\circ} 23,61865^{\prime}$ North, $11^{\circ} 53,03667^{\prime}$ East; field of 2003-04, 51 $23,46484^{\prime}$ North, $11^{\circ} 52,88095^{\prime}$ East). The soil at the field station has a rating index of 94 of 100 possible points (21) and is characterized as clayey silt with loess as the topsoil. For comparison, in the 2003-04 season, we carried out additional field experiments on a field contracted from a local farmer at Salzmünde (federal state of Saxony-Anhalt, Germany, $87 \mathrm{~m}$ above sea level; GPS: $51^{\circ} 30,42894^{\prime}$ North, $11^{\circ} 48,06916^{\prime}$ East). In Salzmünde, the soil is poorer, with a soil rating index of 78 , and is characterized as clayey loam, with loess-pararendzina as the topsoil.

Weather data for the Bad Lauchstädt field station had been gathered since 1895 . The long-time average temperature is $8.7^{\circ} \mathrm{C}$ and average yearly precipitation is $483 \mathrm{~mm}$. Corresponding data were not available for the Salzmünde field. Actual weather conditions during the field experiments were as follows: Bad Lauchstädt October 2002 to August 2003, average temperature $9.4^{\circ} \mathrm{C}$, accumulated precipitation $460 \mathrm{~mm}$; Bad Lauchstädt October 2003 to August 2004, average temperature $9.0^{\circ} \mathrm{C}$, accumulated precipitation $435 \mathrm{~mm}$; Salzmünde October 2003 to August 2004, average temperature $9.0^{\circ} \mathrm{C}$, accumulated precipitation $511 \mathrm{~mm}$

Each field experiment included four replicated blocks. The blocks used a randomized design where each of four variants was represented by a single plot. The plot size was 3 by $12 \mathrm{~m}$. In all experiments, on 15 October, winter wheat cv. Kanzler was sown at a density of 350 grains $/ \mathrm{m}^{2}$ in rows that were $12 \mathrm{~cm}$ apart. This also included a strip of $5 \mathrm{~m}$ that completely surrounded the experiment. The four variants differed by the treatments received during the season. One was always an untreated control, another was a fungicide-treated control that received Pronto Plus at 1.5 liter/ha (Bayer AG, Langenfeld, Germany) and Bravo at 1.0 liter/ha (Syngenta GmbH, Maintal, Germany) at stage 60 on the BBCH (Bundesanstalt, Bundessortenamt and Chemical Industry) scale (11), and a third variant received a treatment with a mycelial suspension of Piriformospora indica of 3,000 liter/ha in total. A treatment with fungicides containing strobilurines was not included to omit putative yield responses caused by a known side effect. The fourth variant differed between the experiments. Both experiments carried out at Bad Lauchstädt included a $P$. indica treatment using 300 liter/ha in total, whereas the fourth variant from Salzmünde included a treatment with 6,000 liter/ha. Treatments with mycelial suspensions of $P$. indica always were carried out twice, at stages 39 and 55 on the $\mathrm{BBCH}$ scale, each time pouring half of the total amount indicated for a given treatment onto the soil using a watering can. None of the variants received any fertilization during the course of the experiment.

We recorded field symptoms caused by several fungal pathogens (i.e., B. graminis f. sp. tritici, Septoria tritici, S. nodorum, Puccinia recondita f. sp. tritici, $F$. graminearum, F. culmorum, and Pseudocercosporella herpotrichoides). Symptoms caused by $P$. herpotrichoides were scored using the same scheme described above for the pot cultures. Scoring of all other disease symptoms relied on published rating schemes (12). Symptoms caused by $S$. tritici and $S$. nodorum were not discriminated. Scoring was performed at the $\mathrm{BBCH}$ stages 55, 69, and 85. It should be emphasized that there were no measures taken to increase the natural load of propagules present at the respective plots.

Wheat was harvested on 1 August 2003 and 12 August 2004 at Bad Lauchstädt and on 13 August 2004 at Salzmünde with a small combine harvester designed for field experiments (Massey Fergusson MF 31; AGCO GmbH, Witzenhausen, Germany). First, strips with a width of $1 \mathrm{~m}$ were removed at both ends of each block so that the length of the lots used for analysis was reduced to $10 \mathrm{~m}$. Then, a strip of $1.68 \mathrm{~m}$ was harvested in the middle of each plot and used for further analysis. The remaining strips of $0.66 \mathrm{~m}$ flanking the former on both sides were discarded. From the entire material harvested from each plot, fresh weights of grains and straw were determined separately. To ascertain the dry weights, two samples of $100 \mathrm{~g}$ each were taken from the harvests of each plot and either directly dried for $24 \mathrm{~h}$ at $105^{\circ} \mathrm{C}$, in the case of straw, or used to determine the water content with a Tecator AP 6060 moisture analyzer (Sinar Technology, Newbury, UK).

Statistical analyses. Analyses were performed with the program JMP (version 4.04; SAS Institute, Cary, NC). We employed the Kruskal-Wallis and $H$ tests to assess variation between infection rates of $P$. herpotrichoides. For all other experiments, we applied the Tukey test to determine significant differences between the variants. The confidence limits were at $95 \%$.

\section{RESULTS}

Piriformospora indica infects and persists in wheat. We determined the potential of $P$. indica to colonize wheat growing in pot cultures using sand and soil as substrata. Root samples were harvested at regular intervals after inoculation and observed by light microscopy (data not shown). $P$. indica grew from the inoculum toward the root and penetrated the rhizodermis. Within 1 week after inoculation, intracellular hyphae became visible in epidermal cells. $P$. indica formed a dense hyphal network around the root within 2 weeks. Chlamydospores were observed within epidermal and root hair cells after 3 weeks. We did not detect any ingress into the stele or the shoot. On both substrata, differentiation progressed in the same way.

In addition, we also used a sensitive PCR approach to monitor the persistence of $P$. indica in wheat roots. In root DNA from inoculated wheat, $P$. indica was detectable at 7 dpi and remained so over a period of 3 months. DNA isolated from wheat roots that grew in sand always yielded more intense bands than those from soil, suggesting more intense colonization (Fig. 1). Taken together, $P$. indica was able to infect and colonize wheat and to persist in host tissues for a considerable time, similarly to what has been reported for other host plants.

Effects of $P$. indica on root, stem-base and leaf diseases of wheat grown in pot cultures. We determined the influence of $P$. indica and $F$. culmorum on germination of wheat seed. In noninoculated controls, germination rates were 99.3 and $97.9 \%$ in garden soil and washed sand, respectively. A significant reduction was observed when $F$. culmorum was inoculated into the soil substratum $(P<0.001)$, resulting in germination rates of $71.4 \%$, which was not found for the sand substratum. When both $P$. indica and $F$. culmorum were inoculated into soil, the germination rate was $90.7 \%$, which was not significantly different from the noninoculated control. Therefore, the detrimental effect of the pathogen was compensated for by the presence of the endophyte. None of the variants from the sand substratum produced

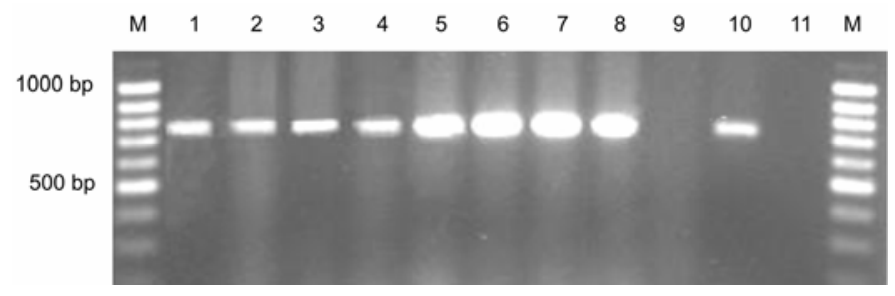

Fig. 1. Polymerase chain reaction (PCR) detection of Piriformospora indica in DNA of wheat roots. $P$. indica was inoculated into pot cultures growing either in soil (lanes 1 to 4 ) or sand (lanes 5 to 8). DNA templates for PCR originate from plants harvested after 7 days (lanes 1 and 5), 14 days (lanes 2 and 6), 30 days (lanes 3 and 7), and 90 days (lanes 4 and 8). Lane 9: root DNA from noninoculated wheat; lane 10: genomic DNA from in vitro cultivated $P$. indica; and lane 11: water control. 
significant differences compared with the respective controls (data not shown).

Next, we assessed the potential of $P$. indica to protect wheat plantlets from the root-pathogen $F$. culmorum, the stem-base pathogen Pseudocercosporella herpotrichoides, and the leaf pathogen $B$. graminis f. sp. tritici. In general, plants grown on sand invested more biomass into roots than into shoots (Fig. 2A). The opposite was true for plants grown in soil (Fig. 2B), where the final total biomass harvested was also much higher than in sand. On soil, the endophyte caused only minor changes to the biomass formation of the host in most cases. In contrast, on sand, Piriformospora indica had prominent beneficial effects because it roughly doubled the biomass. For this variant, the fresh weights of roots, shoots, and the entire plant were increased significantly at all time points tested when compared with the controls (sand roots, 30, 60, 90, and $120 \mathrm{dpi}, P<0.0001$; sand shoots, $30 \mathrm{dpi}, P$ $=0.0008$, and 60, 90, and $120 \mathrm{dpi}, P<0.0001$; sand total, 30, 60, 90 , and $120 \mathrm{dpi}, P<0.0001$; soil roots, $P=0.1112 ; 60 \mathrm{dpi}, P=$ $0.015 ; 90 \mathrm{dpi}, P=0.0615 ; 120 \mathrm{dpi}, P=0.0063$; soil shoots, 30 dpi: $P=0.0014 ; 60$ dpi, $P=0.0002 ; 90$ dpi, $P=0.0037 ; 120 \mathrm{dpi}$, $P=0.0583$; soil total, $30 \mathrm{dpi}, P=0.0343 ; 60 \mathrm{dpi}, P=0.0055 ; 90$ dpi, $P=0.1481$; and $120 \mathrm{dpi}, P=0.3856)$. The biomass gains mediated by the endophyte were smaller in the variant where $F$. culmorum was used for challenge inoculation, but still were significant in relation to the controls.
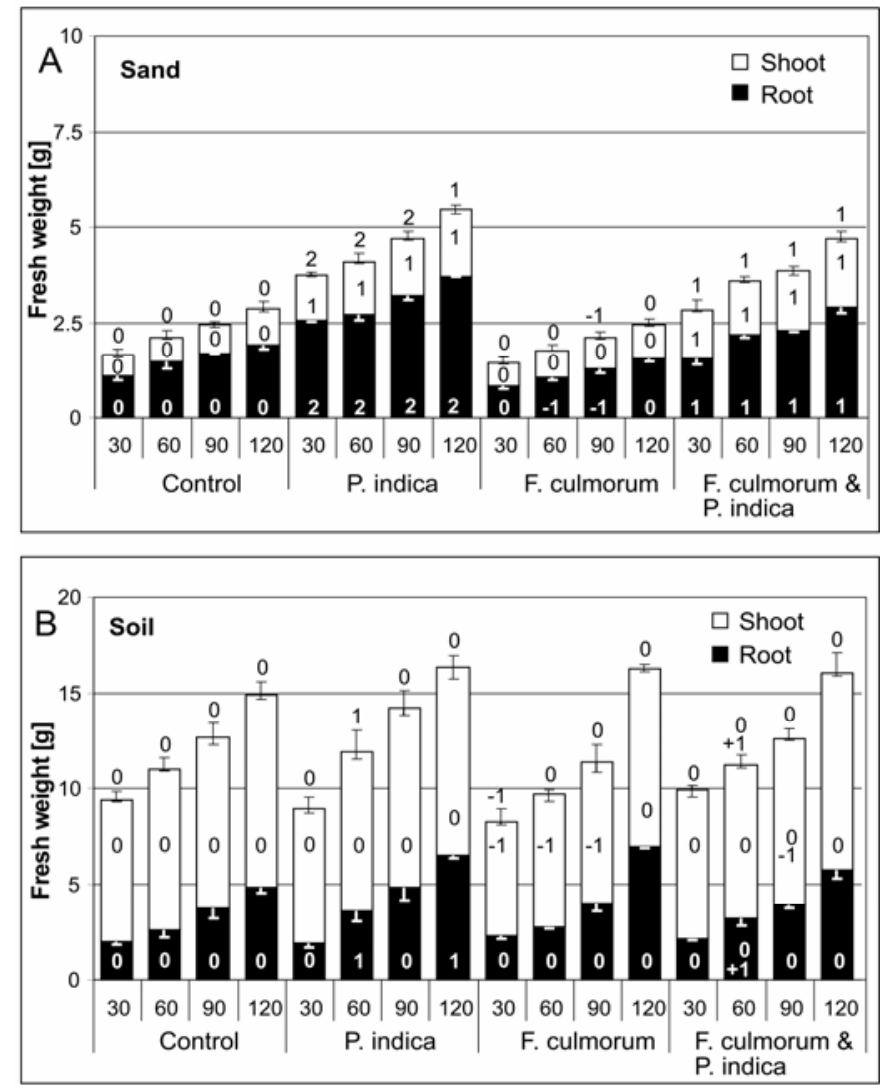

Fig. 2. Effect of Piriformospora indica on biomass production of wheat infected with Fusarium culmorum. Pot cultures were grown in the greenhouse using $\mathbf{A}$, sand or $\mathbf{B}$, soil as the substrata. Columns represent the mean $(n=16$ plants/variant) of total, shoot, and root fresh weights recorded at the indicated day postinoculation (dpi). The upward error bars on top of the columns indicate standard deviation (SD) of the total fresh weight and the downward error bars on the top indicate SD of the shoot fresh weight. The downward error bars within the column represents SD of the root weight. Values that differ significantly from the respective controls (mock inoculation), which were given the significance level 0 , are indicated by numbers. Positive and negative numbers represent different levels of significantly increased and decreased fresh weights, respectively. Columns labeled with two numbers belong to both significance levels.
In assays involving Pseudocercosporella herpotrichoides, in most instances, the pathogen significantly reduced wheat biomass, whereas Piriformospora indica significantly increased wheat biomass compared with the respective controls (sand root, $P=0.0593$; sand shoot, $P=0.0038$; sand total, $P=0.0018$; soil root, $P=0.08$; soil shoot, $P=0.05$; and soil total, $P=0.03$ ) (Fig. $3 \mathrm{~A}$ ).

In variants where $P$. indica was preinoculated, the detrimental effect of the pathogen was not apparent and, in some instances, biomass even increased when compared with the untreated con-
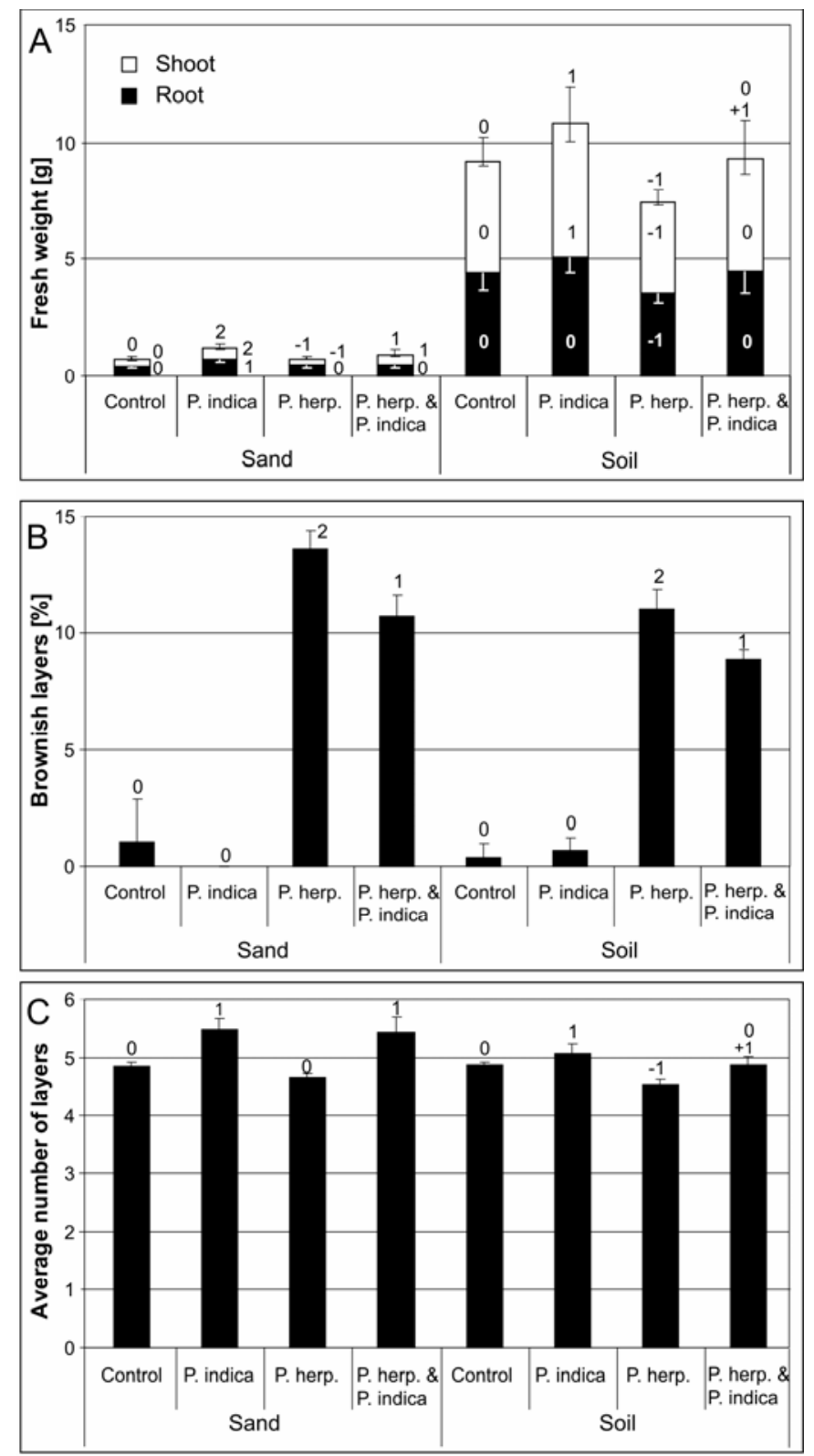

Fig. 3. Effects of Piriformospora indica on wheat infected with Pseudocercosporella herpotrichoides. Plants were grown in sand or soil as the substrata for pot cultures in environmentally controlled growth chambers. Results $(n=60$ plants/variant) were recorded at 60 days postinoculation. Values that differ significantly from the respective controls (mock inoculation), which were given the significance level 0 , are indicated by numbers. Positive and negative numbers represent different levels of significant increases and decreases, respectively. Columns labeled with two numbers belong to both significance levels. A, Columns represent the mean of root, shoot, and total fresh weights. The upward error bars on top of the columns indicate standard deviation (SD) of the total fresh weight and the downward error bars on the top indicate SD of the shoot fresh weight. The downward error bars within the column represents SD of the root weight. B, Columns show the mean and SD of the percentage of sheath layers at the stem base with brownish symptoms. C, Columns show the mean and SD of the average number of sheath layers at the stem base. 
trol. Rating of disease symptoms appearing at the stem base indicated that each individual plant treated with Pseudocercosporella herpotrichoides showed disease symptoms to various degrees. In the absence of $P$. indica, the pathogen produced symptoms in the outer $11 \%$ of leaf sheath layers at the stem bases of soil-grown plants and in the outer $13.6 \%$ of leaf sheath layers at the stem bases of plants grown on sand (Fig. 3B). Preinoculation with $P$. indica significantly reduced symptoms for both substrata $(P<0.0001)$. Importantly, $P$. indica colonization had an effect on the total number of layers formed (Fig. 3C). Plants that were colonized by the endophyte had significantly more layers than the control but also than the variants where the pathogen was used for challenge inoculation (sand, $P<0.0001$ and soil, $P=0.0052$ ). Plants that were infected by Pseudocercosporella herpotrichoides only had fewer layers, which was significant for soil.

In assays involving the powdery mildew fungus $B$. graminis $\mathrm{f}$. sp. tritici, sand-grown plants generally had more pustules per leaf area than the corresponding plants growing on soil (Fig. 4). For all recordings, the variant that was preinoculated with $P$. indica had fewer mildew pustules than the control. Statistical support for this result was obtained for three of six L2 date-leaf-substrate comparisons and for all six L3 comparisons (sand at 3 dpi: L3, $P$ $<0.0001$ and L2, $P=0.0188$; sand at $6 \mathrm{dpi}: \mathrm{L} 3, P=0.0295$ and L2, $P=0.9212$; sand at 9 dpi: L3, $P=0.1853$ and L2, $P=0.8952$; soil at 3 dpi: L3, $P<0.0001$ and L2, $P=0.4178$; soil at 6 dpi: L3, $P=0.0041$ and $\mathrm{L} 2, P=0.0721$; and soil at 9 dpi: L3, $P=0.017$ and L2, $P=0.0445$ ).

To evaluate putative defense reactions of the host, L3 leaves were harvested between 8 and $72 \mathrm{~h}$ postinoculation (hpi) with B. graminis and stained with DAB to visualize hydrogen peroxide in situ. We determined the number of DAB-stained epidermal cells per leaf area of plants grown in sand. Preinoculation of the plant with Piriformospora indica significantly increased the numbers of stained cells at all recordings in comparison with the controls that only used mildew as the inoculum $(8 \mathrm{hpi}, P=$ 0.0177 ; 24 hpi, $P=0.1113 ; 48$ hpi, $P=0.0135$; and 72 hpi, $P=$ 0.0036) (Fig. 5). The average sizes of the DAB-stained spots was not significantly different between $P$. indica-treated and control plants (data not shown).

Effects imposed by $P$. indica on wheat grown in the field. The above experiments established with pot cultures showed that $P$. indica positively affects wheat with respect to biomass and reduction of disease symptoms caused by three fungal pathogens. However, prior to promoting application of $P$. indica in the field, it is essential to assess whether significant effects also are elicited in systems employing conventional agricultural practices. At harvest, we determined grain yields but were unable to record any significant increases mediated by $P$. indica (Fig. 6A). To assess the potential of $P$. indica to produce any effect in the field, we repeated the experiment in the 2003-04 field season at a broader scale. Because the results described above for the pot cultures indicated an effect of the substratum, we set up-in addition to the field in Bad Lauchstädt-a second experiment at a field in Salzmünde that was characterized by poorer soil quality. Furthermore, we increased the amount of mycelial broth of $P$. indica applied as an inoculum at the Salzmünde field. At harvest, we determined straw biomass in addition to grain yield (Fig. 6A). All apparent variation seen for grain yield was again statistically insignificant. However, on the poorer soil of the Salzmünde field, $P$. indica significantly increased straw biomass compared with the untreated control $(P<0.0001)$. Slightly higher straw biomass obtained after a $P$. indica inoculation on the richer soil of the field at Bad Lauchstädt did not prove significant. Fungicide treatment led to significantly higher straw harvests on both soils $(P=$ 0.0732).

Symptoms caused by $F$. culmorum and $F$. graminearum were never detected in any of the experiments; therefore, putative effects exerted by $P$. indica on these pathogens could not be assessed under the prevailing field conditions. All other pathogens occurred in various degrees, depending on the season and the year. None of the symptoms caused by any of the leaf pathogens was reduced significantly by a treatment with $P$. indica when compared with the corresponding controls (data not shown). In contrast, fungicide treatment significantly restricted leaf pathogens in most cases relative to the untreated controls (data not shown). Symptoms caused by $P$. herpotrichoides (i.e., brownish sheath layers at the stem base) did occur in the field and, in most cases, were diminished significantly by $P$. indica $(\mathrm{Bad}$ Lauchstädt: $2003, P=0.0283$ and 2004, $P=0.0406$; Salzmünde: $2004, P=0.0406$ ) (Fig. 6B). This was also the case in 2004, when the pathogen was more prevalent than in 2003. The summer of 2003 was exceptionally hot $(16,18)$, a condition that is unfavorable for $P$. herpotrichoides but advantageous for Piriformospora indica (Fig. 7A). We determined by microscopy whether and to which extent $P$. indica remained detectable at har-

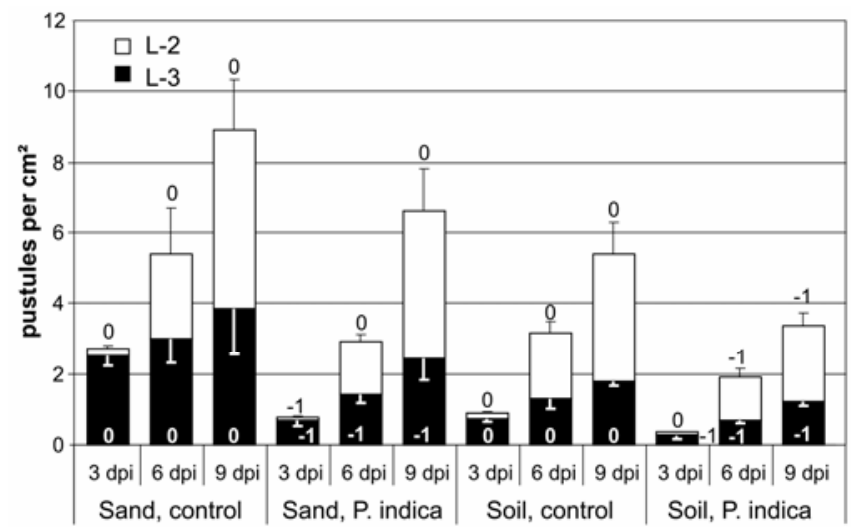

Fig. 4. Effect of Piriformospora indica on pustule formation by Blumeria graminis f. sp. tritici on wheat. Plants were grown in pot cultures in the greenhouse. Inoculation with $P$. indica was done 7 days prior to inoculation with B. graminis. Controls were incubated without receiving an initial $P$. indica inoculum. Columns represent the mean number of pustules and standard deviation ( $n=16$ plants/variant) on L2 and L3 leaves harvested at the indicated days postinoculation (dpi) with powdery mildew conidia; $-1=$ values that are significantly decreased compared with the respective controls (significance level 0).

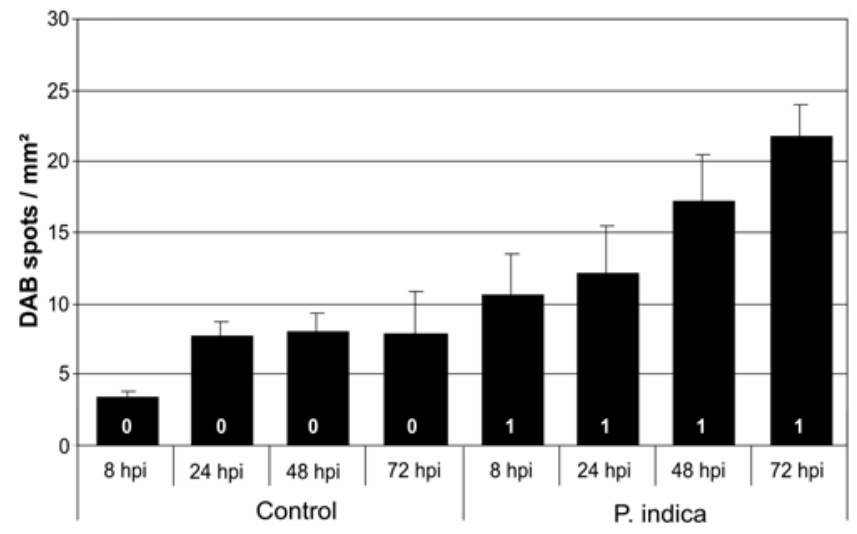

Fig. 5. Effect of Piriformospora indica on hydrogen peroxide formation by wheat after infection with Blumeria graminis f. sp. tritici. Plants were grown in pot cultures in the greenhouse. The $P$. indica variants were inoculated 7 days prior to inoculation with $B$. graminis. Controls were not inoculated with $P$. indica. Columns represent the mean and standard deviation $(n=3$ leaves/variant) of 3,3-diaminobenzidine (DAB)-positive spots counted by microscopy of L3 leaves harvested at the indicated hours postinoculation (hpi) with powdery mildew conidia; $1=$ values that differ significantly from the respective controls (significance level 0 ). 
vest and found the endophyte in all 16 plants that were analyzed for each variant that had received a $P$. indica treatment. The extent of fungal colonization did reflect the inoculation level between 600 and 3,000 liters/ha, but not when it exceeded 6,000 liter/ha $(P<0.0001)$ (Fig. 6C).

In vitro interaction of $P$. indica and Pseudocercosporella herpotrichoides. Because $P$. herpotrichoides was the only pathogen found that was restricted by Piriformospora indica under the prevailing field conditions, we examined the interaction between these two fungi in more detail in vitro. First, the fungi were individually grown at temperatures ranging from 5 to $35^{\circ} \mathrm{C}$ (Fig. 7A). P. indica grew much faster than Pseudocercosporella herpotrichoides at temperatures of $20^{\circ} \mathrm{C}$ and above. The latter did not grow at $30^{\circ} \mathrm{C}$ and above, whereas the former continued to grow up to $35^{\circ} \mathrm{C}$, where an almost maximal growth rate was observed. At the lower end of the temperature range, Piriformospora indica did not grow at $10^{\circ} \mathrm{C}$ and below. In contrast, Pseudo- cercosporella herpotrichoides still grew at $5^{\circ} \mathrm{C}$ with $46 \%$ of the maximal rate. Both fungi grew at the same rate at $\approx 17^{\circ} \mathrm{C}$. Taken together, Piriformospora indica has a temperature profile that clearly differs from that of the local pathogen. In another experiment, both fungi were co-inoculated at opposite ends of the agar and their growth was recorded over the same tempera ture range as described above (Fig. 7A). The growth rates observed for $P$. herpotrichoides were almost unchanged in comparison to the monoculture. However, the growth rates of Piriformospora indica were significantly reduced at 20 and $25^{\circ} \mathrm{C}$ when Pseudocercosporella herpotrichoides was also present $\left(20^{\circ} \mathrm{C}, P=0.0025\right.$ and $\left.25^{\circ} \mathrm{C}, P=0.0007\right)$. These temperatures reflected the optimal conditions for the latter. Neither of the fungi overgrew the other. However, at temperatures from 15 to $25^{\circ} \mathrm{C}$, we observed, at the contact zone, the formation of an indentation at the growing edge of the mycelium of Piriformospora indica (Fig. 7C). At the microscopic level, the
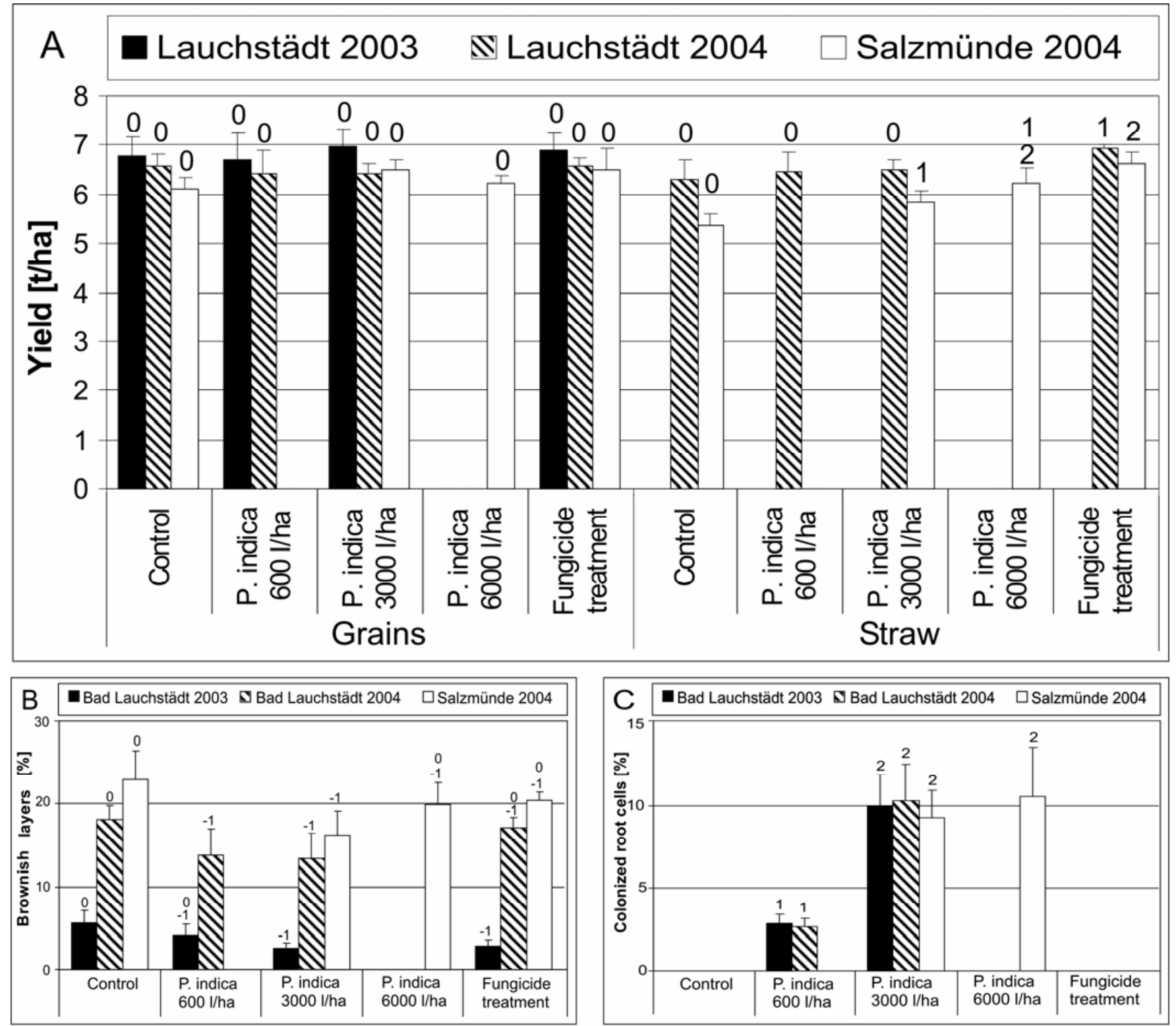

Fig. 6. Effect of Piriformospora indica on wheat in the field. Data were recorded at harvest of field experiments conducted at two locations and in two growth periods. Values that differ significantly from the respective controls (significance level 0 ) are indicated by numbers on top of the columns. Positive and negative numbers represent different levels of significant increases and decreases, respectively. Columns labeled with two numbers belong to both significance levels. A, Biomass production. Columns represent the mean and standard deviation (SD) ( $n=4$ plots/variant) of grain and straw dry weights. B, Disease symptoms caused by Pseudocercosporella herpotrichoides. Columns represent the mean and SD ( $n=200$ plants/variant) percentage of sheath layers with brownish symptoms at the stem base. C, Extent of root colonization by Piriformospora indica. Columns represent the mean and SD ( $n=16$ root segments/variant) of the percentage of root cells stained with chlorazol black E for $P$. indica spores. 

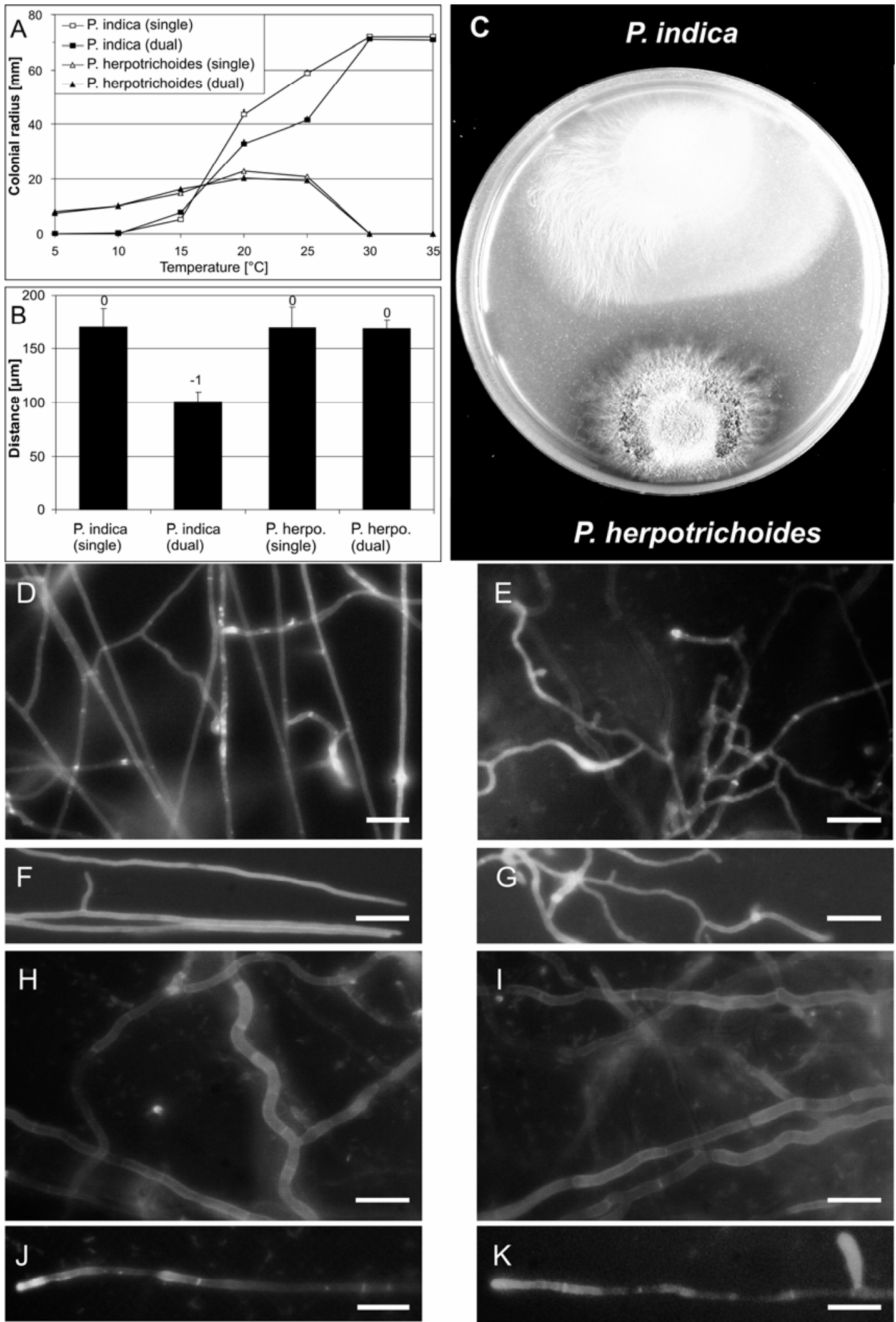

monocultures

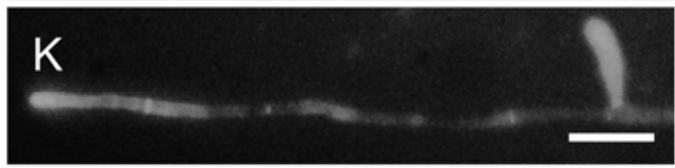

\section{co-cultures}

Fig. 7. Interaction of Piriformospora indica and Pseudocercosporella herpotrichoides in vitro. A, Effect of temperature on fungal growth rates. The fungi were inoculated individually or co-inoculated on opposite sides of a petri dish containing malt extract agar and incubated at the temperatures given at the abscissa. Colonial radii were measured 20 days later. B, Branching at hyphal tips of monocultures and co-cultures. Columns represent the mean distance between the hyphal tip at the edge of colonies and the first branch, and standard deviation $(n=150$ hyphal tips/variant). Values that differ significantly from the respective controls (significance level 0) are indicated by numbers on top of the columns. C, Effect of P. herpotrichoides on mycelial morphology of Piriformospora indica after 24 days of co-culturing at $25^{\circ} \mathbf{C}$. $\mathbf{D}$ to $\mathbf{K}$, Microphotographs from Calcoflour White stained monocultures and co-cultures of $\mathbf{D}$ to $\mathbf{G}$, $P$. indica and $\mathbf{H}$ to $\mathbf{K}$, Pseudocercosporella herpotrichoides showing $\mathbf{D}, \mathbf{E}, \mathbf{H}$, and I, hyphal networks at some distance from the edge of the colony and F, G, J, and K, the hyphal tips at the edge of colonies. Bars $=10 \mu \mathrm{m}$. 
hyphal morphology of $P$. indica was altered when Pseudocercosporella herpotrichoides grew in close vicinity. The mycelium of Piriformospora indica, when grown as a monoculture, formed a regular network (Fig. 7D) with mostly straight hyphae. The hyphal tips appeared straight, with only some branches (Fig. 7F). However, when $P$. indica was co-cultivated with Pseudocercosporella herpotrichoides, the mycelium of the latter appeared more irregular and exhibited curly hyphae (Fig. 7E). The hyphal tips showed more branches that often remained short (Fig. 7G). In contrast, the morphology of hyphae of $P$. herpotrichoides appeared not to be affected by the presence of Piriformospora indica (Fig. 7H and $\mathrm{J}$ versus $\mathrm{I}$ and $\mathrm{K}$ ). We measured the distances of the first hyphal branch from the tip and found a significant difference for $P$. indica when the co-culture was compared with the monoculture $(P=0.0008)$ (Fig. 7B). There was no significant difference for Pseudocercosporella herpotrichoides.

\section{DISCUSSION}

Approximately $80 \%$ of all terrestrial plants growing in their natural habitats, and also many crop plants, associate with AMF that are well known for providing a range of benefits to their hosts. The technical application of AMF in agriculture has been restricted mainly to organic farming systems. Established interactions can improve nutrition, resistance to soilborne pathogens, and tolerance to drought and heavy metals $(6,7)$. However, the application of fertilizers and biocides, tillage, and monocropping decrease the diversity of AMF and confine potential benefits $(3,13,17,19)$. Other difficulties impeding the application of AMF at a broad scale in the field originate from their obligate biotrophic life style, which complicates the production of inoculum. Furthermore, roots normally are colonized by diverse consortia of $\mathrm{AMF}$, where the contribution of individual species to host vitality is poorly understood and the benefits observed are probably a result of complex ecosystem processes in the mycorhizosphere $(1,4,8,10)$.

Piriformospora indica holds some promise for practical application because it is simple to propagate in vitro and accessible to basic physiological and genetic research (25). Furthermore, it presumably has an even wider host range than individual AM species, and the benefits for the host are comparable with that of AMF, although they result from an interaction involving only one fungus and the host. Previously, it had been shown that the basidiomycete $P$. indica exerts several positive effects on colonized host plants when grown in pot cultures $(24,26,28)$. However, it remained uncertain to what extent such results also would be achieved in field experiments that were carried out under regular agricultural conditions. For the work described here, we obtained only a partial confirmation of these earlier results when we treated winter wheat in the field with $P$. indica, which raises doubts as to the broad applicability of $P$. indica for cereal production.

One remarkable feature of $P$. indica is its ability to colonize and benefit a variety of unrelated host plants, which led to the promotion of this endophyte as a putative biofertilizer and biocontrol agent $(26,28)$. Our own pot culture experiments supported this notion because they showed that the interaction of the endophyte with wheat produces a positive effect similar to that reported for other hosts. We were able to prove that $P$. indica colonizes and persists in wheat in a manner comparable with several other plants where this had been tested earlier. The colonization of wheat occurred consistently over the years and conditions tested, even in the field. Additionally, we also observed the reported increase in biomass, but only when a poor sandy substratum was used. The results of the field experiments confirmed this effect of the substratum because significantly enhanced straw production after inoculation with $P$. indica was realized only on the poorer soils of the Salzmünde plots. However, there were only minor, statistically insignificant increases in grain yields. We cannot rule out the possibility that $P$. indica may significantly improve grain yields if the soil quality used for wheat production is poorer than at the Salzmünde field. In a recent study on the interaction of $P$. indica with barley, Mitscherlich pots were incubated outdoors after the cultures had been established in growth chambers (28). A significant increase in grain yield was observed for one of two cultivars tested. For the moment, it is uncertain whether the poor substrate used in these experiments (i.e., loam/sand, 1:2), the use of another host plant, or the seminatural conditions in the experimental set-up can be correlated with that result. In this context, it should be considered that wheat production in Central Europe is carried out mostly on richer soils. Thus, it is uncertain that the application of $P$. indica under conditions similar to ours may ever lead to a significant increase in grain yields. On the other hand, future research may prove the benefits of this endophyte for subsistence slash-and-burn agricultural systems in the tropics, where nutrient depletion and degradation of soils is rapid and leads to abandonment of fields.

Beyond the effect on biomass, $P$. indica diminished the negative impact of F. culmorum, Pseudocercosporella herpotrichoides, and Blumeria graminis f. sp. tritici on winter wheat growing in pot cultures. In the field, we observed significantly fewer symptoms of the stem-base pathogen $P$. herpotrichoides. However, there were no significant differences between the controls and the Piriformospora indica-treated variants for any of the prevalent leaf pathogens, in any of the years, on any of the fields. Thus, contrasting results were obtained for experiments conducted in the greenhouse and in the field. One might argue that $P$. indica may not have persisted in the host during the duration of the field experiment, but the significant positive effect of $P$. indica on straw production suggests that it must have supported the host actively for a considerable time. In addition, we were able to identify the fungus in all plants examined at the end of the field seasons. Furthermore, $P$. indica treatment caused a significant reduction in disease symptoms for the stem-base pathogen Pseudocercosporella herpotrichoides in the field, which also suggests that the fungus has successfully established a persisting interaction. Thus, the apparent incapability of Piriformospora indica to restrict leaf pathogens in the field must have other reasons. This result was surprising because $P$. indica significantly reduced mildew infections in our greenhouse experiments. In addition, it was reported earlier that preinoculation with $P$. indica induced a systemic response in barley that protected leaves from powdery mildew infections (28). These earlier results have raised hopes that $P$. indica may protect its host even better than AMF that are known to be effective only against many soilborne pathogens but not against leaf pathogens (7). Moreover, heavier disease symptoms often are observed on leaves of plants colonized by AMF. In this respect, under the field conditions tested, $P$. indica did not cause significant beneficial or detrimental effects on the prevalence of leaf pathogens. It remains to be shown whether leaf pathogens will be inhibited significantly in fields where disease pressure is much higher than in this study. It seems that greenhouse experiments can predict only to some degree how far the interaction between the endophyte and the host may affect the impact of pathogens under natural field conditions. This again underlines the necessity of regular field experiments to assess the usefulness of fungal endophytes for crop production.

$P$. indica reduced symptoms that were caused by Pseudocercosporella herpotrichoides in the field. To test whether this effect may be linked to the secretion of antifungal proteins or metabolites, we tested sterile-filtered supernatants of liquid cultures from both fungi that grew either alone or as a co-culture. None of the agar-diffusion assays indicated a capability of any fungus to inhibit the other (data not shown). On the other hand, the temperature-dependent growth rates of the two fungi clearly 
differ and reflect their geographical origins. P. herpotrichoides grows fastest at 20 to $25^{\circ} \mathrm{C}$, whereas Piriformospora indica does so at 30 to $35^{\circ} \mathrm{C}$. When the fungi were confronted directly in vitro on solid media, Pseudocercosporella herpotrichoides significantly reduced the growth of Piriformospora indica, but only at its own optimal temperature range. The pathogen also affected hyphal morphology of $P$. indica. In contrast, there was no obvious effect of the endophyte on the pathogen in the in vitro experiments. These findings may appear contradictory to the field data, where we observed an effect of the endophyte on the disease symptoms caused by the pathogen. It should be noted, however, that there might be no direct contact between the two fungi because $P$. indica colonizes the root, whereas Pseudocercosporella herpotrichoides infects the stem base. To our knowledge, the question of how likely a direct encounter of these fungi will be in planta remains experimentally untested. Thus, the reduction of the pathogen may be a result, instead, of induced host defense responses related to the phenomena of systemic acquired resistance (28) or priming (2). Our own experiments support this notion because the number of leaf sheath layers at the stem base increased after an inoculation with Piriformospora indica, and this seemed to be linked to the reduction of symptoms caused by Pseudocercosporella herpotrichoides. Induced host defense responses resulting from a preceding inoculation with Piriformospora indica also are indicated by increased hydrogen peroxide formation in leaves challenged with powdery mildew. However, under field conditions, this host response may not be effective enough or may not be of sufficient duration to control leaf pathogens.

In conclusion, it is questionable whether $P$. indica may serve as a biofertilizer and a biocontrol agent representing a feasible alternative to current practices in cereal production in Central Europe or comparable regions. $P$. indica is not well suited to grow at lower temperatures and, thus, it might be worthwhile to test whether it may increase grain yields on poor soils receiving no fertilizer, especially in hot climates, where it also may be better able to restrict local pathogens.

\section{ACKNOWLEDGMENTS}

Grants provided by the Ministry of Education of the State of SaxonyAnhalt (Jubiläumsstipendium zum 500 jährigen Bestehen der Martin Luther Universität Halle-Wittenberg) to A. Serfling and by the Deutsche Forschungsgemeinschaft (DFG, FOR666, project A1) to H. B. Deising are gratefully acknowledged. We thank B. Look and M. Herrfurth, Bad Lauchstädt, and U. Müller, Salzmünde, for their generous help with the field experiments; S. Reimann and M. Schurig (Martin Luther Universität Halle) for stimulating discussions; B. Saal (Martin Luther Universität Halle) for help with statistics; and P. Franken, U. Sperling, and S. Reimann for providing fungal cultures.

\section{LITERATURE CITED}

1. Burleigh, S. H., Cavagnaro, T., and Jakobsen, I. 2002. Functional diversity of arbuscular mycorrhizas extends to the expression of plant genes involved in P nutrition. J. Exp. Bot. 53:1593-1601.

2. Conrath, U., Pieterse, C. M. J., and Mauch-Mani, B. 2002. Priming in plantpathogen interactions. Trends Plant Sci. 7:210-216.

3. Daniell, T. J., Husband, R., Fitter, A. H., and Young, J. P. W. 2001. Molecular diversity of arbuscular mycorrhizal fungi colonising arable crops. FEMS Microbiol. Ecol. 36:203-209.

4. Dodd, J. C., Boddington, C. L., Rodriguez, A., Gonzalez-Chavez, C., and Mansur, I. 2000. Mycelium of arbuscular mycorrhizal fungi (AMF) from different genera: Form, function and detection. Plant Soil 226:131-151.

5. Ernst, M., Mendgen, K. W., and Wirsel, S. G. R. 2003. Endophytic fungal mutualists: Seedborne Stagonospora spp. enhance reed biomass production in axenic microcosms. Mol. Plant-Microbe Interact. 16:580-587.

6. Gosling, P., Hodge, A., Goodlass, G., and Bending, G. D. 2006. Arbuscular mycorrhizal fungi and organic farming. Agric. Ecosyst. Environ. 113:17-35.

7. Harrier, L. A., and Watson, C. A. 2004. The potential role of arbuscular mycorrhizal (AM) fungi in the bioprotection of plants against soil-borne pathogens in organic and/or other sustainable farming systems. Pest Manage. Sci. 60:149-157.

8. Hart, M. M., and Trevors, J. T. 2005. Microbe management: Application of mycorrhizal fungi in sustainable agriculture. Front. Ecol. Environ. 3:533-539.

9. Hashiba, T., and Narisawa, K. 2005. The development and endophytic nature of the fungus Heteroconium chaetospira. FEMS Microbiol. Lett. 252:191-196.

10. Helgason, T., Merryweather, J. W., Denison, J., Wilson, P., Young, J. P. W., and Fitter, A. H. 2002. Selectivity and functional diversity in arbuscular mycorrhizas of co-occurring fungi and plants from a temperate deciduous woodland. J. Ecol. 90:371-384.

11. Hess, M., Barralis, G., Bleiholder, H., Buhr, L., Eggers, T., Hack, H., and Stauss, R. 1997. Use of the extended BBCH scale-general for the descriptions of the growth stages of mono- and dicotyledonous weed species. Weed Res. 37:433-441.

12. James, W. C. 1971. A Manual of Assessment Keys of Plant Diseases. American Phytopathological Society Press, St. Paul, MN.

13. Jansa, J., Mozafar, A., Kuhn, G., Anken, T., Ruh, R., Sanders, I. R., and Frossard, E. 2003. Soil tillage affects the community structure of mycorrhizal fungi in maize roots. Ecol. Appl. 13:1164-1176.

14. Kumari, R., Kishan, H., Bhoon, Y. K., and Varma, A. 2003. Colonization of cruciferous plants by Piriformospora indica. Curr. Sci. 85:1672-1674.

15. Leach, J., Lang, B. R., and Yoder, O. C. 1982. Methods for selection of mutants and in vitro culture of Cochliobolus heterostrophus. J. Gen. Microbiol. 128:1719-1729.

16. Luterbacher, J., Dietrich, D., Xoplaki, E., Grosjean, M., and Wanner, H. 2004. European seasonal and annual temperature variability, trends, and extremes since 1500. Science 303:1499-1503.

17. Oehl, F., Sieverding, E., Mader, P., Dubois, D., Ineichen, K., Boller, T., and Wiemken, A. 2004. Impact of long-term conventional and organic farming on the diversity of arbuscular mycorrhizal fungi. Oecologia 138:574-583.

18. Ogi, M., Yamazaki, K., and Tachibana, Y. 2005. The summer northern annular mode and abnormal summer weather in 2003. Geophys. Res. Lett. 32:L04706.

19. Plenchette, C., Clermont-Dauphin, C., Meynard, J. M., and Fortin, J. A. 2005. Managing arbuscular mycorrhizal fungi in cropping systems. Can. J. Plant Sci. 85:31-40.

20. Schardl, C. L., Leuchtmann, A., and Spiering, M. J. 2004. Symbioses of grasses with seedborne fungal endophytes. Annu. Rev. Plant. Biol. 55:315-340.

21. Scheffer, F., and Schachtschabel, P. 2002. Lehrbuch der Bodenkunde, 15 ed. Spektrum Akademischer Verlag, Heidelberg, Germany.

22. Schüssler, A., Schwarzott, D., and Walker, C. 2001. A new fungal phylum, the Glomeromycota: Phylogeny and evolution. Mycol. Res. 105:14131421.

23. Sherameti, I., Shahollari, B., Venus, Y., Altschmied, L., Varma, A., and Oelmuller, R. 2005. The endophytic fungus Piriformospora indica stimulates the expression of nitrate reductase and the starch-degrading enzyme glucan-water dikinase in tobacco and Arabidopsis roots through a homeodomain transcription factor that binds to a conserved motif in their promoters. J. Biol. Chem. 280:26241-26247.

24. Singh, A., Sharma, J., Rexer, K. H., and Varma, A. 2000. Plant productivity determinants beyond minerals, water and light: Piriformospora indica-A revolutionary plant growth promoting fungus. Curr. Sci. 79:1548-1554.

25. Varma, A., Singh, A., Sudha, Sahay, N.S., Sharma, J., Roy, A., Kumari, M., Rana, D., Thakran, S., Deka, D., Bharti, K., Hurek, T., Blechert, O., Rexer, K. H., Kost, G., Hahn, A., Maier, W., Walter, M., Strack, D., and Kranner, I. 2001. Piriformospora indica: An axenically culturable mycorrhiza-like endosymbiotic fungus. In: The Mycota IX, Fungal Associations. B. Hock, ed. Springer Verlag, Berlin-Heidelberg.

26. Varma, A., Verma, S., Sudha, Sahay, N., Butehorn, B., and Franken, P. 1999. Piriformospora indica, a cultivable plant-growth-promoting root endophyte. Appl. Environ. Microbiol. 65:2741-2744.

27. Verma, S., Varma, A., Rexer, K. H., Hassel, A., Kost, G., Sarbhoy, A., Bisen, P., Butehorn, B., and Franken, P. 1998. Piriformospora indica, gen. et sp. nov., a new root-colonizing fungus. Mycologia 90:896-903.

28. Waller, F., Achatz, B., Baltruschat, H., Fodor, J., Becker, K., Fischer, M., Heier, T., Huckelhoven, R., Neumann, C., von Wettstein, D., Franken, P., and Kogel, K. H. 2005. The endophytic fungus Piriformospora indica reprograms barley to salt-stress tolerance, disease resistance, and higher yield. Proc. Natl. Acad. Sci. USA 102:13386-13391. 